\title{
A Fixidez da Fantasia na Clínica Contemporânea
}

\author{
Ana Bárbara Andrade ${ }^{1}$ \\ Programa de Apoio ao Pós-Doutorado no Estado do Rio de Janeiro da Pontificia \\ Universidade Católica do Rio de Janeiro, Rio de Janeiro, RJ, Brasil \\ Regina Herzog \\ Programa de Pós-Graduação em Teoria Psicanalítica da Universidade Federal \\ do Rio de Janeiro, Rio de Janeiro, RJ, Brasil
}

\section{Resumo}

O objetivo do artigo é examinar a especificidade da fantasia na clínica contemporânea. Buscaremos analisar a particularidade de um fantasiar de menos valia narcísica que se manifesta de forma privilegiada nesta clínica e os aspectos que o determinam. A fixidez do fantasiar penoso revela-se uma problemática que não só dificulta a mobilidade psíquica do sujeito, como também coloca obstáculos à própria mobilidade da prática psicanalítica. Começaremos por Freud, examinando suas elaborações teóricas a respeito da noção de fantasia, a fim de sublinhar a positividade da atividade prazerosa do fantasiar. Analisaremos ainda as contribuições teórico-clínicas de Winnicott a respeito da imobilidade e estereotipia da vida de fantasia. Nossa hipótese é a de que a especificidade da relação primária que se estabelece entre o infans e a figura materna determina a extensão e mobilidade do fantasiar. Indicaremos que a fixidez da fantasia decorreria de uma relação traumática de submissão absoluta ao objeto primário. Desenvolveremos uma reflexão teórico-clínica a propósito da condução do tratamento analítico com tais pacientes.

Palavras-chave: Fantasia, clínica, psicanálise, contemporaneidade.

\section{The Fixity of Fantasy in Contemporary Clinic}

\begin{abstract}
The goal of this article is to examine fantasy`s specificity in contemporary clinic. We intend to analyze the particularities in a fantasy of narcissist under value that is manifested in a privileged form in this clinic, as well as analyze its determinant aspects. The fixity of painful fantasy reveals itself as a problematic that not only makes psychic mobility difficult for the subject, but it also raises obstacles to the mobility of the psychoanalytic practice itself. We will begin with Freud, examining his theoretical elaborations in respect to fantasy, with the intent to underline the positivity in the pleasurable fantasy activity. We will analyze the theoretical-clinical contributions of Winnicott in respect to the immobility and stereotypic of fantasy life. Our hypothesis is that the specificity of the primary relationship established between the subject and the mother figure determines the extent and the mobility of the fantasy. It is our intention to indicate that the fixity of fantasy comes from a traumatic absolute submission relationship to
\end{abstract}

Endereço para correspondência: Rua Peri, 125/C01, Jardim Botânico. Rio de Janeiro, RJ, Brasil 22460-100. E-mail: barb_andrade@hotmail.com e rherzog@globo.com

Este artigo é derivado da tese de doutorado intitulada $O$ lugar do analista na clínica atual: da fixidez da fantasia à mobilidade psíquica, defendida em 2013 no Programa de Pós-Graduação em Teoria Psicanalítica da Universidade Federal do Rio de Janeiro (UFRJ) e desenvolvida com o apoio financeiro da Coordenação de Aperfeiçoamento de Pessoal de Nível Superior (Capes). 
the primary object. It is also our target to develop a theoretical-clinical reflection about how to conduct the analytical treatment of such patients.

Keywords: Fantasy, clinic, psychoanalysis, contemporarily.

\section{La Fijación de la Fantasía en la Clínica Contemporánea}

\section{Resumen}

El objetivo del artículo es examinar la especificidad de la fantasía en la clínica contemporánea. Buscaremos analizar la particularidad de un fantasear de inferioridad narcisista que se manifiesta de forma privilegiada en esta clínica y los aspectos que lo determinan. La fijación del fantasear penoso se muestra como una problemática que no solo dificulta la movilidad psíquica del sujeto, sino que también coloca obstáculos a la propia movilidad de la práctica psicoanalítica. Comenzaremos por Freud, examinando sus elaboraciones teóricas sobre la noción de fantasía, con el fin de subrayar la positividad de la actividad placentera de fantasear. Analizaremos también las contribuciones teórico-clínicas de Winnicott sobre la inmovilidad y estereotipia de la vida de fantasía. Nuestra hipótesis es que la especificidad de la relación primaria que se establece entre el sujeto y la figura materna determina la extensión y movilidad del fantasear. Indicaremos que la fijación de la fantasía proviene de una relación traumática de sumisión absoluta al objeto primario. Desarrollaremos una reflexión teórico-clínica teniendo como propósito la conducción del tratamiento analítico con tales pacientes.

Palabras clave: Fantasía, clínica, psicoanálisis, contemporaneidad.

"Da minha própria mãe ao materno em mim: que trajetória! Dificil, mas necessária para que haja vida psíquica, mobilidade interna, jogo" (Pontalis, 1988/1991, p. 126).

O presente artigo propõe desenvolver algumas questões relativas ao modo particular de fantasiar do sujeito contemporâneo, o qual impõe desafios à prática clínica atual. Nossa atenção será voltada para certos aspectos da sintomatologia de pacientes, cada vez mais comuns nos consultórios, cuja atividade de fantasiar não se constitui como fonte de prazer. A amplitude reduzida de seu campo fantasmático se manifesta, na cena analítica, por meio de uma expectativa negativa e cruel em relação a si mesmo e ao mundo, sendo possível notar em seus conteúdos imaginários um sentimento de si depreciado e desprestigiado. Assim, o que se destaca neles, no modo como se conduzem no processo analítico, é fundamentalmente uma dificuldade em fantasiar com prazer.

Devido a uma autopercepção profundamente desvalorizada, o sentimento de menos valia comparece, no tratamento com estes pacientes, como sofrimento predominante. Observa-se uma propensão a forjar mentalmente, e quase de modo exclusivo, cenas em que o desprazer é privilegiado. De acordo com Costa (2012), estes sujeitos são desprovidos de amor próprio, de tal modo que apresentam "dificuldade de se perceber como um suporte de narrativas positivas e não apenas de narrativas por subtração: eu não sou; eu não posso; eu não sei; eu não desejo; eu não quero; eu não penso e assim por diante" (Costa, 2012, p. 12).

Ao conferir intensa indignidade ao próprio sentimento de si, o espaço psíquico desses sujeitos mostra-se emperrado em termos de plasticidade e de mobilidade. A vida psíquica destes pacientes é dominada, de forma recorrente, por um fantasiar estereotipado de caráter penoso e doloroso, com uma sequência de cenas em que se imaginam duramente desvalorizados. As cenas imaginárias de menos valia narcísica perfilam em seu mundo psíquico. É a repetição contínua destas cenas aflitivas que lhes confere um caráter de compulsão à repetição, fenômeno clínico que, conforme indicado por Freud (1920), é capaz de determinar a reprodução de experiências que não incluem qualquer possibilidade de prazer e que 
conduzem, em última instância, para a dimensão traumática presente nesses funcionamentos psíquicos.

Tal modo de sofrimento subjetivo é suscetível de se apresentar em diversos quadros da psicopatologia psicanalítica, uma vez que a singularidade penosa e compulsiva do fantasiar pode tanto ser remetida ao modelo clínico da neurose obsessiva, como ao da histeria e, ainda, ao quadro melancólico. A respeito de sua possível ressonância com o quadro obsessivo, mais evidente, vemos nessas configurações clínicas um sofrimento psíquico relacionado à incerteza sobre si, antecipações mentais de autoacusação, entre outros sintomas muito semelhantes àqueles da neurose obsessiva.

Quanto à comparação com o modelo clínico da melancolia, não podemos deixar de considerar que esses pacientes dão sinais, ainda mais evidentes, de sua semelhança com o sujeito melancólico. As autorrecriminações, sintoma típico da melancolia, sobre o qual nos fala Freud ([1915]1917/1974e), que se manifesta no melancólico sem que ele tenha qualquer constrangimento, é indicativo desta correlação. ${ }^{2}$ Entretanto, nossa intenção aqui não é a de estabelecer comparações com um determinado modelo nosológico, mas, antes, a de evidenciar um modo de sofrimento psíquico que pode transitar entre diferentes quadros clínicos, apresentando sinais diversos tanto de sintomatologias neuróticas quanto melancólicas. Isto é, pretendemos nos centrar na natureza desse fantasiar de menos valia, entendendo-o como a especificidade de um mundo imaginário penoso que pode se apresentar em pacientes com configurações clínicas heterogêneas, ainda que todos apresentem uma problemática narcísica predominante.

As dificuldades referidas ao campo fantasmático em tais casos dizem respeito, portanto, a uma dificuldade de ter prazer ao criar fantasias. A problemática parece se afinar com a observa-

2 A respeito de uma leitura comparativa entre o modelo metapsicológico da melancolia e as patologias narcísicas, remetemos o leitor a Pinheiro, 2012; Pinheiro, Quintella, \& Verztman, 2010; Verztman, 2012. ção de Green (1979/1988b) quanto ao modo de funcionamento psíquico de sujeitos com uma problemática narcísica central, cujos transtornos na esfera do pensamento, bastante frequentes, indicam um funcionamento marcado por uma prevalência da pulsão de morte sobre o princípio de prazer. Seu funcionamento psíquico, segundo Green, estaria orientado de maneira inversa à lógica descrita no texto freudiano, de 1911/1974d, sobre os dois princípios básicos do funcionamento mental:

É como se o sujeito dissesse "sim" ao desprazer e "não" ao prazer. Em muitos casos o analista pensa que o "não ao prazer" está meramente na superfície e que existem satisfações escondidas para essa manutenção do sofrimento. Porém existem outros casos em que a dor psíquica é tal que parece difícil acreditar que o sujeito recebe, enfim, qualquer satisfação dela. (Green, 1979/1988b, p. 28)

Esse quadro clínico, ao sugerir uma dominância da pulsão de morte sobre o psiquismo, inviabiliza a instauração da atividade fantasmática em seu aspecto mais essencial. Isso porque a noção de fantasia, se nos pautarmos, de início, na definição de Aulagnier (1990), apresenta como característica central o fato de "preservar um prazer em pensar que não tenha outra razão que o puro prazer de criar esse pensamento" (Aulagnier, 1990, p. 263). O vínculo entre o princípio de prazer e a atividade de fantasiar é, portanto, indissociável, fato que poderemos constatar ao retomarmos a construção teórica freudiana relativa à noção de fantasia. Vejamos como Freud buscou assinalar a natureza prazerosa do fantasiar.

\section{O Estatuto da Fantasia em Freud}

Na obra freudiana, a definição de fantasia admite uma estreita correlação com o princípio de prazer. Para Freud (1911/1974d), a capacidade de fantasiar abre para o sujeito um campo de experiências criativas onde ele pode, na imaginação, prescindir das exigências da realidade, as quais exigem dele uma renúncia da satisfação e o adiamento do prazer. $\mathrm{Na}$ dimensão da 
fantasia, ao criar uma encenação imaginária na qual pode figurar como um dos participantes da cena, o sujeito se afasta dos sentimentos aflitivos e tem assegurada a realização de um desejo. A atividade de fantasiar é definida assim como uma modalidade de pensamento que prescindiria do teste de realidade, permanecendo subordinada ao princípio de prazer. Nesta perspectiva, as fantasias seriam a condição de possibilidade das brincadeiras infantis, na medida em que, ao brincar, a criança daria ensejo aos primeiros traços de atividade imaginativa, sendo capaz de criar um mundo próprio, ajustando-o do modo que mais lhe agrada.

Como ilustração da prevalência, na fantasia, do princípio de prazer, vale destacar a organização do "romance familiar" (Freud, [1908]1909) como uma das modalidades típicas de encenações fantasmáticas. Na criação de seu romance familiar, o sujeito neurótico consegue modificar imaginariamente, a seu bel-prazer, o enredo de sua própria história familiar infantil. Constrói seu romance familiar de modo a tornar mais satisfatória a imagem das figuras parentais.

As teorias sexuais das crianças também se configuram como expressão da dimensão imaginativa infantil. Essas teorias buscam dar uma resposta àquilo que, para a criança, se apresenta como um importante enigma a respeito de sua origem. A indagação sobre o nascimento - "De onde vêm os bebês?" - exige uma explicação, à qual a criança se esforça por responder e, para isso, recorre ao fértil reino da fantasia, apoiando-se em observações extraídas da realidade para dar forma às suas investigações (Freud, 1908/1974c). Tais pesquisas sexuais são sempre realizadas na solidão e podem ser entendidas como uma primeira etapa, por parte da criança, no processo de assunção de uma atitude independente do mundo. Dessa forma, fica subentendida a exigência de separação eu-outro para a instauração da fantasia, quando a criança o faz de modo autônomo e independente (Freud, 1908/1974c). Retomaremos a questão mais adiante.

O reino da fantasia, contudo, não se restringe à infância, mas conserva-se presente e atuante na vida adulta. Como substituto das brincadeiras infantis, o devaneio pode ser entendido como uma continuação do brincar das crianças, sendo capaz de preservar ao longo da vida psíquica uma forma de atividade do pensamento independente do teste de realidade (Freud, 1911/1974d). $\mathrm{O}$ fantasiar do adulto pode ser entendido, dessa maneira, como uma atividade herdeira daquilo que, na vida psíquica infantil, era a única modalidade de pensamento do sujeito, submetido exclusivamente ao princípio de prazer (Laplanche \& Pontalis, 1977). Herda-se, assim, da vida imaginativa infantil, a capacidade de acessar, de forma fluida e plástica, um estado psíquico em que há o predomínio do princípio de prazer. Deste modo, a fantasia, na vida adulta, passa a funcionar como uma zona de passagem entre a realidade objetiva e a dimensão imaginativa. Compreende-se, portanto, o fantasiar como uma zona de transição entre o princípio de realidade e o princípio de prazer. Como bem esclarece Green (1988c), a fantasia seria uma das figuras mais eloquentes entre as formações do inconsciente que vem atestar a natureza onipotente do pensamento. Trata-se, assim, de um modo privilegiado de manifestação do narcisismo infantil, sobre o qual se sustenta a estrutura das fantasias.

O que mais merece destaque na análise da noção de fantasia em Freud é a sua natureza mutável e maleável, claramente presente na noção de devaneio, modelo prototípico da fantasia. "Não devemos supor", diz ele, "que os produtos dessa atividade imaginativa - as diversas fantasias, castelos no ar e devaneios - sejam estereotipados ou inalteráveis" (Freud, [1907]1908/1974b, p. 153). Ao contrário, o conteúdo das fantasias seria constantemente alterado, sucessivamente variável em função das diferentes vivências do sujeito, ganhando novos enredos a cada mudança de situação - "recebendo de cada nova impressão ativa uma espécie de 'carimbo de data de fabricação"” (Freud, [1907]1908/1974b, p. 153). Esse movimento dinâmico do fantasiar, sua extraordinária plasticidade, permite ao sujeito obter prazer através da realização de desejo. Sendo assim, a organização da fantasia pode ser entendida, por definição, como uma representação da relação que o sujeito estabelece com o desejo e o prazer (Aulagnier, 1979). A contínua remodelagem da fantasia - suas expressões sucessivas 
- confere ao psiquismo toda a sua potencialidade de metamorfose, capaz de conduzir o sujeito em direção à realização de desejo, quando pode flutuar entre os três tempos abrangidos pelo pensamento. A consideração sobre a importância da temporalidade na construção da fantasia se justifica pelo fato de que nela, "o passado, o presente e o futuro são entrelaçados pelo fio do desejo que os une" (Freud, [1907]1908/1974b, p. 153). O presente pode ser transformado na fantasia, apoiando-se, de um lado, no passado da onipotência infantil e voltando-se, de outro, para o futuro projetado pelo desejo de mudança. Deste modo, as fantasias teriam a função de aspirações que, mobilizadas por uma experiência de onipotência narcísica e dispondo de plasticidade psíquica, visam uma modificação da realidade insatisfatória (Freud, [1907]1908/1974b).

Ora, se o pensamento freudiano ressalta o caráter positivo do fantasiar, entendido como trabalho psíquico profícuo no sentido de uma abertura para o prazer e a mobilidade do desejo, como compreender a fixidez fantasmática dos pacientes contemporâneos? A dificuldade apresentada por eles, mais do que uma ausência da fantasia, refere-se precisamente a uma paralisia de sua plasticidade e mobilidade para fantasiar. Em suas fantasias não se nota uma relação com a temporalidade que comporte uma imbricação entre passado, presente e futuro, tal como postulado por Freud (Freud, [1907]1908/1974b). A paralisia da fantasia parece estar associada, nesses casos, a uma experiência psíquica do tempo congelado, como se não houvesse abertura para modificações projetadas em um tempo futuro, modificações que seriam vislumbradas a partir de seu mundo imaginário. Em tais condições, suas fantasias são estáticas, sem mobilidade psíquica, não fazendo conexões com o passado, por um lado, e mantendo-se fixadas numa narrativa penosa sobre o cotidiano da vida atual, por outro.

Além disso, a onipotência do narcisismo infantil, característica também central do fantasiar prazeroso, não comparece nas configurações psíquicas mencionadas, as quais manifestam, ao contrário, uma fantasia de menos valia narcísica, oposta a qualquer ideia de onipotência e prazer. Fato que indica a primazia da pulsão de morte no psiquismo desses sujeitos, produzindo um fantasiar dominado por conteúdos dolorosos, cuja insistência se impõe repetidamente ao sujeito. Imposição que funciona como uma força "que está absolutamente decidida a apegar-se à doença e ao sofrimento" (Freud, 1937/1974h, p. 276), determinando um modo de funcionamento psíquico em que "a busca de prazer substitui-se a si própria pela busca do desprazer" (Green, 1979/1988b, pp. 27-28) - característica já apontada acima a respeito do sofrimento psíquico do sujeito contemporâneo.

Esta "busca do desprazer" parece se aproximar dos fenômenos derivados do funcionamento masoquista (Freud, 1923/1974f). O sentimento de culpa inconsciente e sua consequente necessidade de autopunição, manifestando-se por uma tendência ao sofrimento, desempenhariam um papel decisivo na economia psíquica desses pacientes, sem, contudo, como sublinha Green (1979/1988b), implicar uma tentativa de obter uma satisfação oculta com esse sofrimento. O fantasiar penoso pode ser entendido, assim, como expressão de um masoquismo moral, caracterizado, nesses casos, por um modo de fantasiar que assume um conteúdo insistentemente negativo, visando exclusivamente o desprazer, em que "o próprio sofrimento é o que importa" (Freud, 1924/1974g, p. 206).

Sendo assim, nos perguntamos o que pode estar na base da fixidez do fantasiar penoso observada atualmente na clínica? O que impede esses pacientes de experimentar prazer na atividade de fantasiar? Nossa hipótese é a de que tal constelação psíquica, cuja dificuldade central se situa em uma fixidez da fantasia de menos valia narcísica, decorreria de um traumatismo precoce em sua relação com o ambiente. Tratar-se-ia mais propriamente de um fracasso do processo de separação eu-não-eu. Tal fracasso pode ser remetido, por um lado, a uma relação com o objeto primário marcada por uma ausência de investimento libidinal, ou, por outro, a uma relação com o objeto em que o investimento teria sido demasiado. Ambas as vivências de caráter excessivo. Pretendemos, a seguir, identificar as possíveis relações entre a imobilidade do fantasiar e o excesso de presença do objeto primário 
em sua constituição subjetiva. A nosso ver, esse modo de relação objetal contribui significativamente para certo emperramento da mobilidade do psiquismo para fantasiar com prazer.

\section{O Tempo Rítmico da Relação Primária}

O estabelecimento das condições psíquicas propícias ao fantasiar é determinado, entre outros fatores, pela temporalidade e pela qualidade rítmica da relação mãe-bebê. De acordo com Winnicott (1968/2012), nas experiências iniciais do lactente com o ambiente, as modulações do ritmo materno - tanto através dos movimentos fisiológicos da mãe, como nos cuidados dedicados ao lactente - imprimem inflexões na vida psíquica do bebê. A experiência inaugural do tempo, tal como é vivenciado pelo bebê, é descrita nos seguintes termos pelo autor: "O tempo não se mede tanto por relógios, pelo nascer ou pelo pôr do sol, quanto pelo ritmo do coração e da respiração maternos, pela elevação e queda das tensões instintivas" (Winnicott, 1968/2012, p. 84). É com base nestas comunicações silenciosas entre mãe e bebê, quando ocorre uma adaptação materna sensível às necessidades da criança, que o bebê pode ter a experiência de confiabilidade no objeto materno, experiência crucial para que siga a trajetória desde a dependência absoluta à dependência relativa estabelecida com a mãe (Winnicott, 1968/2012). Após este período de desenvolvimento inicial, o bebê pode experimentar os breves períodos de ausência da mãe, mantendo a figura materna viva psiquicamente. Os intervalos de investimento materno funcionam, assim, como um tempo fundamental para a criança criar e manter o objeto primário vivo na realidade psíquica interna. Nestes intervalos, abre-se um espaço psíquico propício para que a criança dê início à própria vida imaginativa (Andrade \& Herzog, 2014).

A propósito, Fain (1971) se refere a casos em que a pouca fluência da atividade de fantasiar determina sintomas precoces no bebê, sintomas relacionados à incapacidade de suportar períodos de ausência materna. $\mathrm{O}$ autor cita o caso de bebês insones que só se acalmam e adormecem quando embalados, de forma contínua e ininterrupta, nos braços das mães. Qualquer afastamento materno é capaz de interromper o sono e provocar os gritos e choros do bebê. Segundo o autor, teria havido, nesses casos, falhas na função de pára-excitação materna no início do desenvolvimento psíquico do bebê, impedindo-o de criar uma forma de atividade psíquica favorável ao sono, quando o movimento de fantasiar e a atividade onírica poderiam garantir a manutenção do sono. Nessas condições patológicas, o papel de guardião do sono passa a ser exercido pelas próprias mães. É como se o corpo real das mães ocupasse, aí, o lugar do objeto primário, no caso, insuficientemente interiorizado (Mcdougall, 1974).

O trabalho psíquico tem início, no bebê, graças à experiência de acúmulo de tensão ocasionada na espera pela satisfação pulsional, o que coloca seu aparelho psíquico em ação. Neste registro, os gritos e a agitação motora do bebê, ainda que não funcionem como descarga eficaz, operam como 'aviso' dirigido ao objeto primário para que a experiência de satisfação venha a se repetir (Freud, [1895]1950/1974a). Se a mãe se antecipa, atendendo a criança antes mesmo que o grito tenha lugar, estará impedindo que esta efetue o trabalho psíquico, qual seja, a possibilidade de investir alucinatoriamente a vivência de satisfação. Nestas situações, "ele [bebê] precisa fazer pouco, quase nada, para que a mãe compareça" (Kehl, 2009, p. 228). A precipitação por parte da mãe em atender a demanda do bebê, precipitação que pode ser continuamente repetida, dá pouca oportunidade ao filho de se movimentar psiquicamente para realizar alucinatoriamente o seu desejo (Kehl, 2009).

Do mesmo modo, a demora excessiva em atender à demanda do bebê, devido a um investimento insuficiente por parte da figura materna, também impede a experiência prazerosa através da qual a criança realizaria alucinatoriamente $o$ desejo. $\mathrm{O}$ tempo de intervalo entre a satisfação de suas demandas, quando prolongado por mais tempo do que o seu psiquismo suporta, conduzirá a uma experiência traumática, experiência psíquica da ordem de um excesso pulsional. É, portanto, como decorrência do ritmo entre ausência e presença de investimento materno que 
o bebê pode experimentar sua capacidade imaginativa (Andrade \& Herzog, 2014). Assim sendo, como esclarece Winnicott (1971/1975), a adaptação sensível do ritmo materno às necessidades do bebê é determinante para a criação do momento de ilusão tão fundamental para o processo de constituição psíquica. Quando a mãe se adianta ou se atrasa demais a este ponto do tem$p o$, ela impede que a criança dê ensejo à atividade prazerosa de fantasiar. Cabe à mãe assegurar à criança, em respeito ao seu ritmo próprio, a capacidade imaginativa de iludir-se em seu movimento de inventar algo (Winnicott, 1971/1975).

As experiências de ausência objetal são, portanto, cruciais para a constituição psíquica do sujeito. Neste contexto inicial, quando ocorre um investimento materno benéfico, as experiências de ausência do objeto permitem que a criança simbolize sua ausência, criando em seu psiquismo uma representação do objeto materno. Roussillon (2008) assinala a importância da experiência de ausência do objeto no processo de simbolização: "o objeto ausente perceptivamente, mas presente em outro lugar, representado junto a um outro, não é mais um objeto perdido, ou melhor, é perdido-encontrado, é ausente-perdido na percepção e re-encontrado na psique, presente nela, tornado presente "re-presentado"" (Roussillon, 2008, p. 110).

A instauração da atividade de pensar e de fantasiar do sujeito decorreria, assim, da possibilidade de re-presentar o objeto primário no momento de sua ausência, já que "é na ausência do objeto que a representação dele é formada, a fonte de todo pensamento" (Green, 1975/1988a, p. 48). É quando a criança, no processo de separação eu-outro, pode dominar psiquicamente a experiência de ausência do objeto, mantendo o investimento erótico dirigido ao objeto na fantasia - processo fundamental para a criação de um "espaço secreto pessoal" (Green, 1975/1988a, p. 61).

\section{A Submissão ao Outro: Uma Contribuição de Winnicott}

A natureza de uma relação objetal que não reconhece a existência singular do infante, a qual inscreve o sujeito em uma posição de submissão radical ao outro, é um tema de discussão que atravessa a obra winnicottiana. Por parte do sujeito, a fim de resistir à posição de submissão, sobrevém uma resposta defensiva que buscará salvaguardar a parte sensivel de seu psiquismo. Tal parte sensivel seria justamente aquela onde se encontraria a matéria plástica e móvel do seu fantasiar criativo.

Um tema bastante recorrente em seus escritos é precisamente a problemática clínica decorrente da dificuldade em fantasiar criativamente. O autor desenvolve uma reflexão valiosa sobre as diferenças qualitativas entre modos distintos de atividade fantasmática ${ }^{3}$ e, como ilustração, apresenta o caso clínico de uma paciente que revela certa imobilidade em seu mundo de fantasia (Winnicott, 1971/1975) - caso que nos interessa particularmente, merecendo aqui uma reflexão mais atenta.

O repertório fantasmático da paciente se expressava por uma atividade de devaneio estéril de natureza compulsiva, ocupando todo seu funcionamento psíquico. A esterilidade de seu fantasiar se revelava, entre outros fatores, no sentimento de que a sua vida não tinha sentido; tratava-se de fantasias vazias sem relação com os objetos de sua realidade, já que nada em sua existência tinha para ela valor significativo. Segundo Winnicott (1971/1975), a problemática clínica da paciente, uma mulher de meia-idade, estaria relacionada a questões decorrentes do que o autor designa como "dissociação primária", mais do que ao recalque - concepção próxima a de clivagem narcísica proposta por Ferenczi (1931/2011). O modo de sofrimento psíquico da paciente de Winnicott (1971/1975) corresponde, de forma muito próxima, ao modo de sofrimen-

\footnotetext{
Convém uma ressalva a respeito da terminologia empregada por Winnicott (1971/1975). O autor contrapõe os termos "sonhar" e "fantasiar", a fim de indicar que o primeiro implicaria uma atividade criativa e o segundo, uma atividade estática. Preferimos manter o enfoque na noção de fantasia, e, desse modo, à luz das contribuições de Winnicott, contrapomos a fantasia móvel e plástica, de um lado, a qual corresponde ao "sonhar" winnicottiano, e a fantasia estática, de outro.
} 
to psíquico que analisamos aqui - sujeitos cuja vida imaginária penosa permanece como fenômeno isolado, exigindo trabalho psíquico, mas funcionando como uma atividade estática.

Ao longo do trabalho de análise com Winnicott, a paciente descobre que a parte principal de sua existência se realizava precisamente em devaneios estéreis, que ocorriam "quando ela não estava fazendo absolutamente nada" (Winnicott, 1971/1975, p. 49). Enquanto este 'não fazer absolutamente nada' se encobria em certas atividades fúteis, a paciente se entregava a uma atividade fantasmática dissociada, em um estado de ausência de si que só lhe confirmava o sentimento de que não existia. O sentimento de ausência de si era descrito "como se não pudesse ficar em sua pele" (Winnicott, 1971/1975, p. 53) ou como se não pudesse "possuir-se a si mesma" (p. 54).

É possível destacar do argumento de Winnicott (1971/1975) uma oposição entre o fantasiar estático, mesmo que dotado de um movimento compulsivo, e o fantasiar criativo, este sim positivado e considerado como atividade criativa. Para o autor, a capacidade de fantasiar criativamente implicaria a possibilidade fértil da imaginação, isto é, uma forma de exploração imaginária do mundo que pode enriquecer a vida psíquica, um lugar em que "sonho e vida são a mesma coisa" (Winnicott, 1971/1975, p. 46). Em outros termos, na fantasia criativa, o material se comunicaria com a vida e os objetos investidos pelo sujeito, de tal modo que o material fantasiado seria carregado de valor simbólico. O material fantasiado teria "camada sobre camada de significado relacionado ao passado, ao presente e ao futuro" (Winnicott, 1971/1975, p. 56), podendo tanto referir-se a experiências da vida precoce infantil do sujeito, como a projeções futuras. A indicação quanto ao aspecto temporal presente no fantasiar nos remete diretamente à definição freudiana, já assinalada anteriormente (Freud, [1907]1908/1974b, p. 153).

No caso, a atividade fantasmática da paciente de Winnicott (1971/1975), ao contrário, não parece abrir-se seja para o passado, presente ou futuro, mas permanece incomunicável, restringindo-se à parte dissociada do eu. Essa paciente incorreria em uma superprodução de fantasias que pode ser entendida justamente como o oposto da atividade de fantasiar (Pontalis, 1988/1991). Atividade de caráter compulsivo que parece responder a uma "obrigação de imaginar", na qual "o desenvolvimento de uma atividade frenética de jogo não é feito dentro de uma liberdade de brincar" (Green, 1988c, p. 250). São observações que podem contribuir para compreender a fixidez do fantasiar penoso do sujeito contemporâneo. Trata-se igualmente de um fantasiar estático, desprazeroso, contrapondo-se à mobilidade e à liberdade pressuposta no fantasiar prazeroso.

O modo de funcionamento psíquico descrito sugere que, na relação objetal primitiva, deve ter havido uma incapacidade do objeto primário em reconhecer a diferença, a incapacidade de favorecer, na criança, a expressão criativa de sua própria singularidade. A dificuldade de fantasiar com prazer decorreria, assim, de uma complacência e submissão do sujeito ao outro. Como afirma Winnicott (1971/1975), em um modelo de relação de submissão ao outro dessa ordem:

. . . o mundo em todos os seus pormenores é reconhecido apenas como algo a que ajustar-se ou a exigir adaptação. A submissão [grifos nossos] traz consigo um sentimento de inutilidade e está associada à ideia de que nada importa e de que não vale a pena viver a vida. . . . como se estivessem presos à criatividade de outrem, ou de uma máquina (Winnicott, 1971/1975, p. 95).

A ênfase colocada sobre a submissão e o ajustamento adaptativo indica um modo particular de relação objetal, caracterizado pela impossibilidade de aquisição de autonomia psíquica por parte do sujeito. As experiências que permitiriam o fantasiar criativo do sujeito seriam asseguradas, portanto, na medida em que este pudesse ser reconhecido como sujeito singular - contrariamente ao que teria ocorrido nos casos aqui investigados. $\mathrm{O}$ objeto primário parece ter se sobreposto ao sujeito, invalidando a expressão de sua autonomia psíquica, dificultando os seus movimentos de separação e diferenciação. 
O fracasso do processo de separação $e u$ -não-eu fragiliza o sentimento de existência e abala a estabilidade narcísica do sujeito, podendo ser vivido como ameaça de desintegração e morte psíquica. Diante dessa ameaça, uma resposta possível, encontrada pelo sujeito, é a de se manter fixado à expressão estereotipada de seu fantasiar penoso. Isto é, o sentimento de si depreciado e desvalorizado, que se manifesta em seu fantasiar, pode ser entendido como um modo pelo qual o sujeito garante a recomposição de sua identidade, uma saída para defender-se do risco de desintegração egóica. Justamente por isso, em lugar de ver no fantasiar penoso desses sujeitos um aspecto negativo, podemos dizer que o sentimento de menos valia, inerente ao seu fantasiar, acaba por compor o seu eu, sua unidade narcísica. Mas é preciso sublinhar, como elucida Tisseron (2007), que o sujeito paga um preço para promover tal reconstituição identitária, já que "a apropriação do sentimento de existência se dá às expensas do sentimento de valor. $\mathrm{O}$ sujeito se reunifica, mas como sujeito indigno" (Tisseron, 2007, p. 52, tradução nossa).

\section{A Fabulação de Fantasias em Análise}

O manejo clínico em análise, diante de pacientes que muito dificilmente esboçam fantasias de caráter prazeroso, revela-se um desafio para o analista. Como lidar clinicamente com um repertório fantasmático tão reduzido e estático? Sabe-se que uma constatação recorrente, atualmente, é de que a técnica psicanalítica clássica se mostra insuficiente para uma abordagem clínica com determinados pacientes - os "casos difíceis", refratários à análise. Neste sentido, as experimentações técnicas de Ferenczi, cuja atualidade vem sendo confirmada através do crescente interesse por sua obra dentro do campo psicanalítico, colocam questões valiosas para pensar a prática clínica com esses pacientes. Algumas de suas elaborações concernentes à "técnica ativa" (Ferenczi, 1921/2011a), mais especificamente quando propõe o dispositivo técnico das "fantasias provocadas" (Ferenczi, 1924/2011b), são ilustrativas quanto à especificidade do lugar do analista no tratamento de tais casos. ${ }^{4}$

Ferenczi propõe um método clínico que funcionaria como um "jogo das fantasias" (1931/2011, p. 87), elaborado para tratar pacientes que, segundo ele, apresentavam uma atividade fantasmática estagnada, ou, ao contrário, pacientes "cujos sintomas consistiam em repetidos devaneios diurnos . . que os fazia extraviarem-se pelos caminhos da fantasia patológica" (Ferenczi, 1924/2011b, p. 262). Em alguns casos, ele intimava o paciente, através de ordens e injunções, a criar fantasias ou reações afetivas ausentes de seus relatos, visando, com tal procedimento, que eles chegassem a vivenciar afetivamente suas fantasias. Em outros casos, era o próprio Ferenczi quem emprestava suas fantasias, comunicando ao paciente o que imaginava que este provavelmente teria sentido ou pensado em determinada situação. Desse modo, o autor propõe que o analista crie, a partir de seu próprio fantasiar, uma trama imaginativa em análise, com o objetivo de que o paciente venha a segui-lo neste trabalho, produzindo seu próprio conteúdo. Com esta intervenção mais ativa por parte do analista, Ferenczi visava restituir, ao paciente, uma atividade psíquica em que a "imaginação ganha 'embalo"' (Ferenczi, 1924/2011b, p. 263).

Julgamos que o valor deste tipo de recurso clínico não se encontra prioritariamente na especificidade técnica, cujas injunções ativas, a depender do caso, implicariam o risco de produzir efeitos de submissão no paciente. Trata-se mais de valorizar a perspectiva que se abre no que diz respeito ao papel do analista no manejo desses casos. O que se exige do analista, notadamente, é a vitalidade de sua própria capacidade de elaboração imaginativa, diante de pacientes cuja imobilidade psíquica impõe "um intenso esforço de pensamento, a fim de procurar pensar aqui-

4 Uma discussão a respeito da técnica das "fantasias provocadas" (Ferenczi, 1924/2011b) foi desenvolvida de forma mais detalhada em trabalho anterior (Andrade, Mello, \& Herzog, 2012). Retomamos aqui alguns pontos desta discussão, em uma articulação com o contexto clínico da fixidez do fantasiar. 
lo que o paciente é incapaz de pensar" (Green, 1975/1988a, p. 48). Deste modo, mais importante do que os conteúdos ou representações específicos presentes nas fantasias do analista, destacamos da inspiração ferencziana o fato de que a comunicação do fantasiar por parte do analista permite que o paciente seja testemunha de uma vitalidade na produção do pensar e representar. Trata-se de uma aposta clínica em que o analista, por meio do próprio exercício fantasístico, poderia vir a favorecer, no paciente, a atividade de fantasiar com prazer (Andrade et al., 2012).

A fantasia, como área privilegiada de passagem entre o princípio de realidade e o princípio de prazer, revela-se, assim, em toda a sua potência, como condição de possibilidade para a mobilização do tempo congelado do traumático. Ao enfatizarmos o fato de que o valor da atividade de fantasiar com prazer está em sua capacidade de remanejar as condições psíquicas estáticas do presente para abrir-se a uma expectativa de futuro, buscamos indicar um sentido para a direção do tratamento com esses pacientes. A direção do tratamento deve tentar promover a transposição de um estado psíquico marcado pelo domínio da onipotência do objeto primário traumático para um novo estado em que o sujeito pode começar a crer na onipotência dos próprios desejos encenados na fantasia.

Quando o sujeito pode enfim abrir-se para um devir, ele se inscreve em uma experiência psíquica inaugural, a partir da qual pode imaginar a existência de novos mundos. Este aspecto de abertura psíquica é enfatizado por Birman (2012), ao explorar o sentido da experiência do sonho, contrapondo-o à experiência perceptiva. Segundo o autor, quando sonhamos, temos aberta "uma janela para a experiência de outros mundos possíveis" (Birman, 2012, p. 14). Assim, se aproximamos a experiência do sonho à experiência da fantasia, tal como nos indica Freud ([1907]1908/1974b), podemos depreender desta correlação que a atividade de fantasiar com prazer permite, do mesmo modo, a abertura psíquica para outros mundos possíveis. $\mathrm{Na}$ dimensão imaginativa da fantasia, o sujeito se põe a inventar futuros possíveis. Este é um dos desafios que se apresenta ao analista ao deparar-se com as subjetividades atuais, exigindo dele ampla mobilidade e plasticidade psíquica a fim de colaborar no movimento transferencial para que o analisando, a seu próprio modo, forje novos mundos.

\section{Referências}

Andrade, A. B. \& Herzog, R. (2014, 4-7 set.). Imobilidade da fantasia na clínica: Sofrimento psíquico como descrédito de si. Trabalho apresentado no VI Congresso Internacional de Psicopatologia Fundamental e XII Congresso Brasileiro de Psicopatologia Fundamental, Belo Horizonte, MG, Brasil.

Andrade, A. B., Mello, R., \& Herzog, R. (2012). A associatividade na clínica psicanalítica atual: Considerações sobre a técnica. In J. Verztman, T. Pinheiro, R. Herzog, \& F. Pacheco-Ferreira (Eds.), Sofrimentos narcísicos (pp. 229-250). Rio de Janeiro, RJ: Cia. de Freud.

Aulagnier, P. (1979). A violência da interpretação: Do pictograma ao enunciado. Rio de Janeiro, RJ: Imago.

Aulagnier, P. (1990). O direito ao segredo: Condição para poder pensar. In P. Aulagnier, Um intérprete em busca de sentido: Vol. I (pp. 258-279). São Paulo, SP: Escuta.

Birman, J. (2012). O sujeito na contemporaneidade. Rio de Janeiro, RJ: Civilização Brasileira.

Costa, J. F. (2012). Os sobrenomes da vergonha: Melancolia e narcisismo. In J. Verztman, T. Pinheiro, R. Herzog, \& F. Pacheco-Ferreira (Eds.), Sofrimentos narcísicos (pp. 9-15). Rio de Janeiro, RJ: Cia. de Freud.

Fain, M. (1971). Prélude à la vie fantasmatique. Revue Française de Psychanalyse, 35(2-3), 291-364.

Ferenczi, S. (2011a). Prolongamentos da "técnica ativa” em psicanálise. In S. Ferenczi, Psicanálise III (pp. 117-135). São Paulo, SP: Editora WMF Martins Fontes. (Original publicado em 1921)

Ferenczi, S. (2011b). As fantasias provocadas (atividade na técnica da associação). In S. Ferenczi, Psicanálise III (pp. 261-269). São Paulo, SP: Editora WMF Martins Fontes. (Original publicado em 1924)

Ferenczi, S. (2011) Análises de crianças com adultos. In S. Ferenczi, Psicanálise IV (pp. 79-95). São Paulo, SP: Editora WMF Martins Fontes. (Original publicado em 1931) 
Freud, S. (1974a). Projeto para uma psicologia científica. In Edição Standard Brasileira das Obras Completas de Sigmund Freud: Vol. I. Rio de Janeiro, RJ: Imago. (Original publicado em [1895]1950)

Freud, S. (1974b). Escritores criativos e devaneios. In Edição Standard Brasileira das Obras Completas de Sigmund Freud: Vol. IX. Rio de Janeiro, RJ: Imago. (Original publicado em [1907]1908)

Freud, S. (1974c). Sobre as teorias sexuais das crianças. In Edição Standard Brasileira das Obras Completas de Sigmund Freud: Vol. IX. Rio de Janeiro, RJ: Imago. (Original publicado em 1908)

Freud, S. ([1908]1909). Romances familiares: Vol. $I X$. Rio de Janeiro, RJ: Imago.

Freud, S. (1974d). Formulações sobre os dois princípios do funcionamento psíquico. In Edição Standard Brasileira das Obras Completas de Sigmund Freud: Vol. XII. Rio de Janeiro, RJ: Imago. (Original publicado em 1911)

Freud, S. (1974e). Luto e melancolia. In Edição Standard Brasileira das Obras Completas de Sigmund Freud: Vol. XIV. Rio de Janeiro, RJ: Imago. (Original publicado em [1915]1917)

Freud, S. (1920). Além do princípio do prazer: Vol. XVIII. Rio de Janeiro, RJ: Imago.

Freud, S. (1974f). O ego e o id. In Edição Standard Brasileira das Obras Completas de Sigmund Freud: Vol. XIX. Rio de Janeiro, RJ: Imago. (Original publicado em 1923)

Freud, S. (1974g). O problema econômico do masoquismo. In Edição Standard Brasileira das Obras Completas de Sigmund Freud: Vol. XIX. Rio de Janeiro, RJ: Imago. (Original publicado em 1924)

Freud, S. (1974h). Análise terminável e interminável. In Edição Standard Brasileira das Obras Completas de Sigmund Freud: Vol. XXIII. Rio de Janeiro, RJ: Imago. (Original publicado em 1937)

Green, A. (1988a). O analista, a simbolização e a ausência no contexto analítico. In A. Green, Sobre a loucura pessoal (pp. 36-65). Rio de Janeiro, RJ: Imago. (Original publicado em 1975)

Green, A. (1988b). A psicanálise e modos comuns de pensamento. In A. Green, Sobre a loucura pessoal (pp. 23-35). Rio de Janeiro, RJ: Imago. (Original publicado em 1979)
Green, A. (1988c). Narcisismo de vida, narcisismo de morte. São Paulo, SP: Escuta.

Kehl, M. R. (2009). O tempo e o cão: A atualidade das depressões. São Paulo, SP: Boitempo.

Laplanche, J., \& Pontalis, J.-B. (1977). Vocabulário de psicanálise. Rio de Janeiro, RJ: Martins Fontes.

McDougall, J. (1974). Le psyché-soma et le psychanalyste. Nouvelle Revue de Psychanalyse, 10, 131-150.

Pinheiro, T. (2012). O modelo melancólico e os sofrimentos da contemporaneidade. In J. Verztman, T. Pinheiro, R. Herzog, \& F. Pacheco-Ferreira (Eds.), Sofrimentos narcísicos (pp. 17-38). Rio de Janeiro, RJ: Cia. de Freud.

Pinheiro, T., Quintella, R. R., \& Verztman, J. (2010). Distinção teórico-clínica entre luto, depressão e melancolia. Psicologia Clínica, 22(2), 147-168. doi:10.1590/S0103-56652010000200010

Pontalis, J.-B. (1991). Perder de vista: Da fantasia de recuperação do objeto perdido. Rio de Janeiro, RJ: Jorge Zahar. (Original publicado em 1988)

Roussillon, R. (2008). L'entreje(u) primitif et l'homosexualité primaire "en double". In R. Roussillon, Le jeu et l'entre-je(u) (pp. 107-134). Paris: Presses Universitaires de France.

Tisseron, S. (2007). La honte: psychanalyse d'um lien social. Paris: Dunod.

Verztman, J. S. (2012). A melancolia e o olhar: Uma clínica contemplativa? In N. Coelho Junior, P. Salem, \& P. Klautau (Eds.), Dimensões da intersubjetividade (pp. 105-124). São Paulo, SP: Escuta.

Winnicott, D. W. (2012). A comunicação entre o bebê e a mãe e entre a mãe e o bebê: Convergências e divergências. In D. W. Winnicott, $O s$ bebês e suas mães (4. ed., pp. 79-92). São Paulo, SP: Editora WMF Martins Fontes. (Original publicado em 1968)

Winnicott, D. W. (1975). O Brincar e a realidade. Rio de Janeiro, RJ: Imago, 1975. (Original publicado em 1971) 